\title{
Questões estratégicas e de segurança internacional: a marca do tempo e a força histórica da mudança
}

EUGÊNIO VARGAS GARCIA*

As questões estratégicas e de segurança internacional tiveram o seu espaço na Revista Brasileira de Política Internacional ao longo dos anos, embora não com a mesma intensidade que apareciam em outras revistas e periódicos voltados especificamente para esses assuntos. A preocupação dos editores da RBPI pareceu ser sempre a vinculação entre os temas estratégicos e a política externa brasileira, ou seja, ter presente o impacto para a inserção internacional do país, seja ele positivo ou negativo, de debates, decisões ou políticas na área de segurança.

Um dos exemplos da importância atribuída pelos editores da Revista à discussão sobre assuntos estratégicos foi o número especial sobre "Temas Militares" (XIV, 53-54, 1971). Entre os artigos daquele número alguns poderiam ser destacados: "O continente americano dentro da problemática mundial” (João Augusto de Araújo Castro), "Dissuasão e industrialização" (André Beaufre), "Segurança estratégica” (Nelson Lavenère-Wanderley), “A arte do comando na guerra nuclear” (José Maria de Toledo Camargo), e “As Forças Armadas e a integração da Amazônia” (Rodrigo Otávio Jordão Ramos). Ao final do volume, além dos documentos e das seções costumeiras de resenhas de livros, o leitor era ainda brindado com 61 páginas de uma bibliografia específica sobre temas militares, a qual incluía livros publicados no Brasil e no exterior, organizados por assunto, ampla relação de artigos e lista de periódicos especializados.

É interessante constatar que, em tempos de ameaça de guerra nuclear entre as superpotências, e sendo os estrategistas obrigados a "pensar no impensável”, os desconcertantes cenários que poderiam ser imaginados levavam às vezes à produção de estranhos textos (aos olhos do observador situado no final do século), alguns com finais melancólicos, como o do Coronel Toledo Camargo: "Não adiantarão tropas eficientes e condicionadas para o combate nuclear; chefes hábeis nas técnicas de comando e dominando os segredos das ciências humanas; infraestrutura sólida e arsenal bem fornido. Será sempre a fé a verdadeira força capaz de empolgar um povo, movimentar um exército e levá-lo ao objetivo, ainda que este não represente senão um amontoado de ruínas radioativas”. Esses textos eram, entretanto, reflexos de um momento histórico particular.

\footnotetext{
* Doutorando em História das Relações Internacionais pela Universidade de Brasília e diplomata.
} 
Não obstante a ênfase nos temas de interesse direto para o Brasil, como se verá a seguir, artigos sobre questões mais gerais também apareciam com certa regularidade. Penner da Cunha, por exemplo, publicou em dois números (XV, 59-60, 1972 e XVI, 61-62, 1973) um estudo sobre "Aspectos da paz armada”, no qual analisava a evolução histórica de formas de hegemonias baseadas no "poder militar relativo" (PRM) em cada um dos períodos estudados: Pax Romana, Pax Christiana, Pax Britannica e Pax Americana. Adota-se como premissa que, na sua expressão mais geral, a paz gerada pela conquista produz-se em uma extensa área geográfica pela imposição de um poder predominante sobre entidades políticas ali pré-existentes, mas com a ressalva de que o poder assim aplicado não é sempre, nem é apenas, físico: "pode ser fruto da fermentação de idéias que passam a gozar de aceitação generalizada, como ocorreu com o Cristianismo”. Do estudo de Penner da Cunha, na parte relativa à Pax Britannica, extraímos um parágrafo sobre a teoria do equilíbrio de poder que permanece atual, já que o conceito ainda hoje é largamente utilizado na análise das relações internacionais, tanto por teóricos quanto por historiadores:

"A idéia de que se poderia identificar em política internacional um princípio tão constante quanto uma lei física explica a aceitação da doutrina do equilíbrio de poder. Estava dentro da tradição cientificista do momento [século XIX] tentar reduzir a formas exatas constatações susceptíveis de generalização. Ademais, os êxitos políticos ingleses e as idéias do laissez-faire induziram a aceitação desse mecanismo regulador automático. (...) Na verdade, ainda quando prevaleça um estado que se define, talvez à falta de melhor termo, de equilíbrio, é de certo exagero dizer que ocorre de forma automática ou sequer semi-automática. O que é quase espontâneo é o observador antecipar um equilíbrio nas relações de política internacional, pois de outro modo como se explicaria que o Estado mais forte abdicasse de exercer sua força? (...) É claro que a teoria convinha à Inglaterra, cujas características nacionais distinguiam-na em tudo das demais nações européias. Insular, marítima, monárquica, colonial, industrial, liberal, pôde desfrutar e defender um 'esplêndido isolamento' apenas quebrado pela necessidade de intervir para restaurar o equilíbrio de poder. Talvez essas características expliquem melhor do que a própria construção intelectual porque em geral se considera a teoria do equilíbrio um sistema britânico. Não existe, na verdade, perfeita coincidência entre a realidade e o delineamento teórico, mas, em grandes linhas, a preocupação inglesa era impedir a afirmação de uma potência que lhe criaria problemas, levando em conta sua grande dependência externa”.

Na Série Brasília da RBPI, questões atuais de segurança internacional continuaram a ser abordadas na revista. O Embaixador Amaury Porto de Oliveira, por exemplo, pesquisador do Instituto de Estudos Avançados da USP, no artigo “O Leste asiático em tempos de monopolaridade” (Ano 39, n² 2, 1996), analisou o problema da reformulação da política de segurança regional na Ásia-Pacífico, 
envolvendo os Estados Unidos, a Rússia e os países asiáticos (sobretudo Japão e China), no contexto do pós-Guerra Fria. Trata-se de tema oportuno, pois na ÁsiaPacífico do momento presente uma das questões centrais a ser respondida é a de se saber se as nações asiáticas escolherão o caminho do progresso, pela continuidade pacífica dos fluxos de comércio e de investimentos recíprocos, ou se, ao contrário, sucumbirão às tentações da Realpolitik, revivendo velhos diferendos bilaterais e adormecidas veleidades de potência, com repercussões negativas para a estabilidade regional.

Em seu texto, o Embaixador Amaury Porto de Oliveira põe em relevo os interesses estratégicos e econômicos em jogo na Ásia-Pacífico e problematiza os grandes temas atualmente em discussão sobre o assunto: a presença militar norteamericana na região e o futuro da aliança EUA-Japão, a questão de Taiwan, o comportamento da China e a oscilação da política norte-americana entre "contenção" e "engajamento", as tentativas de maior aproximação entre Moscou e Pequim, os dilemas enfrentados pelo Japão para assumir o papel militar de um "país normal”, entre outros. Nunca é demais lembrar que persistem tensões em torno de disputas territoriais que envolvem vários Estados, de que são exemplos: a) as reivindicações de soberania sobre as Ilhas Spratlys (ou Nanchas); b) a posse das Ilhas Paracell, confrontando China e Vietnam; c) o domínio sobre a Ilha Senkaku (ou Diaoyu), opondo China e Japão; d) o direito sobre as Ilhas Tok-Doh (ou Takeshima), rivalizando Japão e Coréia; e e) o contencioso entre o Japão e a Rússia em relação às Kurilas do Sul. O artigo finaliza pondo em relevo a criação do Foro Regional da ASEAN (ARF), em 1994, cuja finalidade é reforçar a cooperação mútua, incluindo medidas de construção de confiança, desenvolvimento de mecanismos de solução de conflitos e diplomacia preventiva. O autor sugere que o ARF, como instrumento de negociação multilateral surgido por iniciativa de potências pequenas e médias, talvez seja o mecanismo mais adequado à disposição dos países asiáticos para tentar encaminhar, por meio da "busca paciente do consenso, em um processo gradual de somas e adequações”, soluções consentâneas com suas próprias tradições.

Vejamos, a seguir, como se desenvolveram três grandes temas que, de acordo com a orientação da RBPI de privilegiar a reflexão sobre os assuntos ligados ao Brasil, foram recorrentes ao longo desses 40 anos: desarmamento e nãoproliferação nuclear; o poder militar no Brasil e o papel das Forças Armadas; e segurança e política de defesa do Brasil.

\section{Desarmamento e não-proliferação nuclear}

No Brasil, o interesse pela utilização da energia nuclear para fins pacíficos já existia de forma incipiente desde o advento da era atômica propriamente dita, ao final da Segunda Guerra Mundial. Os fatores políticos que envolviam a posse 
do conhecimento para o enriquecimento do urânio, porém, cedo se fizeram sentir sobre o país e, em 1945, era assinado um acordo com os Estados Unidos comprometendo-se os dois países à consulta prévia na exportação de materiais nucleares. Daquela época até os anos 50, merece destaque o trabalho pioneiro do Almirante Álvaro Alberto, entusiasta do desenvolvimento da tecnologia nuclear no Brasil e um dos criadores do CNPq. Os governos militares, a partir de 1964, superada a fase inicial de estabilização financeira e de reformas econômicas e administrativas, reformularam em muitos pontos as diretrizes da política energética brasileira, que igualmente acompanhava a maior complexidade que o país ia adquirindo, com reflexos na área externa.

O debate sobre o desarmamento no âmbito das Nações Unidas, nos anos 60 , mereceu especial atenção da $R B P I$, tendo sido reproduzidos vários discursos e documentos sobre a posição do Brasil na matéria, incluindo a Conferência sobre Desarmamento em Genebra, onde o Brasil, reafirmando então sua postura de independência em relação a qualquer bloco político-militar, propôs a substituição do binômio "desarmamento e inspeção" pelo trinômio "desarmamento, inspeção e reconversão econômica”. Em discurso pronunciado na 39a Sessão da Conferência sobre Desarmamento (V, 19, 1962), Afonso Arinos de Melo Franco fez a defesa do "desarmamento geral e completo", para o qual todos os Estados, incluindo as grandes potências nucleares, deveriam devotar esforços com base na confiança mútua e independentemente de diferenças ideológicas.

Em 1967, um número especial da Revista foi dedicado à política nuclear (X, 37-38, 1967), justamente no momento em que se discutia os termos do Tratado de Não-Proliferação de Armas Nucleares (TNP), concluído no ano seguinte, ao qual o Brasil não aderiu por considerá-lo injusto e discriminatório. Publicou-se naquele número amplo material sobre a política brasileira de energia atômica, desde pronunciamentos do Presidente da República e do Ministro das Relações Exteriores até análises sobre as características e aplicações das explosões nucleares para fins pacíficos, incluindo aspectos técnicos, jurídicos, científicos e político-militares. A Nota Liminar que introduzia o volume, assinada por José Honório Rodrigues, refletia bem o espírito da época:

"Como o poder mundial é transitório - e o de Portugal e Espanha foi fugaz como um meteroro - , obedecer e conformar-se com a política fixada pelos Poderes atuais significa abandonar todas as perspectivas que a energia nuclear própria oferece como um feixe de inacreditáveis possibilidades. (...) A política de energia atômica própria que o Brasil defende pode vir a ser o fator decisivo nos próximos séculos, e o nosso futuro pode ficar comprometido, caso não mantivermos a unidade destes três elementos fundamentais: a soberania, a energia atômica e o desenvolvimento".

Havia aparentemente uma sintonia fina entre autoridades governamentais, militares, diplomatas, e grande número de acadêmicos e cientistas, todos 
convergindo no apoio à política traçada pelo Presidente Costa e Silva, que, em discurso proferido em 1967, anunciava haver instruído o Ministro das Minas e Energia a, em estreita colaboração com a Comissão Nacional de Energia Nuclear (CNEN), elaborar um programa de produção comercial de eletricidade, com base na energia do átomo, que incluísse uma recomendação específica em relação à "oportunidade, dimensão e local da instalação da primeira usina geradora nucleoelétrica”, que posteriormente teria seu sítio escolhido no município de Angra dos Reis (RJ). Afirmava o Presidente:

"O Governo brasileiro se reservará o direito de total exclusividade, quanto à instalação e operação de reatores nucleares, bem como às operações de pesquisa, lavra, industrialização e comercialização de minerais e minérios nucleares, materiais férteis, materiais físseis e materiais físseis especiais. Criará condições para a formação, no País e no exterior, do pessoal técnico-científico, especializado no campo da energia nuclear, de níveis médio e superior, na quantidade e nos prazos necessários à pesquisa científica, que será intensificada no território nacional”.

A posição do Brasil em relação ao TNP, por sua gravidade naquele contexto de Guerra Fria, acabou tendo reflexos no discurso diplomático. Araújo Castro, Chanceler no governo João Goulart e mais tarde Chefe da Missão Permanente do Brasil junto à ONU e Embaixador em Washington, destacou-se pela elaboração de uma visão brasileira do cenário internacional que se coadunava perfeitamente com a estratégia que vinha sendo seguida na área nuclear. Em 1970, no artigo "Fundamentos da paz internacional: balança de poder ou segurança coletiva" (XIII, 49-50, 1970), Araújo Castro tece considerações sobre algumas das teses que a ele seriam depois permanentemente associadas, como a do "congelamento do poder mundial” e a da necessidade de revisão da Carta das Nações Unidas.

Araújo Castro sustenta que o TNP estava baseado em uma teoria de diferenciação entre "nações adultas responsáveis e poderosas” e "nações não poderosas" que, por isso mesmo, seriam "não responsáveis e não adultas". A premissa fundamental do TNP era a de que, contrariamente à experiência histórica, o poder geraria a moderação e traria consigo a responsabilidade. O perigo estaria nos países desarmados e não nos vastos e sempre crescentes arsenais das superpotências. Ao conferir poderes e prerrogativas especiais às nações que atingiram o status de "adultas" na era nuclear, continuava o Embaixador, o TNP consagrava o poder e promovia "uma institucionalização sem disfarce da desigualdade entre os Estados".

As "oito conclusões e um sumário" com que Araújo Castro encerra seu artigo são um bom exemplo da forma como o Brasil concebia, no limiar da década de 1970, sua inserção estratégica internacional, e vale a pena reproduzi-las aqui:

“i) para os países menores, Paz é sinônimo de Segurança e significa, de maneira muito direta, soberania, integridade territorial e imunidade contra agres- 
são ou ocupação estrangeira. A idéia de Justiça vincula-se assim, naturalmente, à idéia de Paz. A Paz não tem o mesmo sentido para todas as nações e o mesmo pode ser dito quanto à Segurança;

ii) nem a balança de poder nem a segurança coletiva estão hoje em condições de oferecer uma base sólida e firme para a Paz internacional. A balança de poder tornou-se obsoleta e a segurança coletiva ainda não amadureceu. É uma questão de "não mais" no primeiro caso e de "não ainda" no segundo;

iii) os esforços comuns ora realizados pelas Superpotências, valendo-se da "arte sutil da co-presidência”, visam ao congelamento e à estabilização do poder à base de duas datas arbitrárias (25 de junho de 1945, data da assinatura da Carta das Nações Unidas, e $1^{\circ}$ de janeiro de 1967, data limite para as nações se habilitarem como estados militarmente nucleares, nos termos do Tratado de NãoProliferação de Armas Nucleares);

iv) no léxico das Grandes Potências o conceito de desarmamento está sendo superado pela expressão "controle de armamentos" ou "limitação de armamentos”. Os esforços comuns por elas desenvolvidos visam antes à manutenção da presente ordem internacional e à prevenção de uma conflagração nuclear em escala mundial que ao estabelecimento de uma Paz e Segurança permanentes entre as nações em consonância com os princípios e objetivos da Carta de São Francisco;

v) em jargão diplomático, “realismo” passou a significar a aceitação passiva do poder como a única medida capaz de aferir os atos dos homens e as atividades das nações;

vi) embora os mecanismos contemplados pela Carta das Nações Unidas se tenham revelado inadequados e inoperantes, seus princípios e objetivos permanecem tão válidos hoje quanto o eram em 1945 e possivelmente permanecerão válidos no futuro previsível;

vii) o Conselho de Segurança, que fora anteriormente paralisado pelo veto, é agora freqüentemente paralisado pelo “consenso" ou pela "unanimidade”. Dada a impossibilidade prática de aplicação das medidas coercitivas previstas no Capítulo VII da Carta, o melhor caminho aberto ao Conselho de Segurança no momento atual consistiria no desenvolvimento e no aperfeiçoamento de suas atribuições nos termos do Capítulo VI. Até que se proceda a uma revisão da Carta, será necessário um esforço criador mais consistente para que se chegue à utilização plena dos meios e mecanismos ao alcance do Conselho de Segurança e de toda a Organização para a solução pacífica de controvérsias internacionais;

viii) o vigésimo quinto aniversário das Nações Unidas deveria oferecer uma oportunidade para reafirmação dos princípios e objetivos da Carta de São Francisco. Ninguém pode afirmar que esses princípios deixaram de resistir à prova do tempo. Não obstante, é verdade que foram freqüentemente ignorados, desrespeitados ou violados. A tarefa que se impõe às Nações Unidas é a de transfor- 
mar esses ideais em realidade. As Nações Unidas podem representar apenas uma tênue esperança de Paz. Mas não existem outras esperanças”.

Ao manter-se à margem do TNP, o Brasil procurava mostrar as vantagens do Tratado de Proscrição das Armas Nucleares na América Latina (Tlatelolco, México), de 1967, o primeiro tratado de criação de uma zona livre de armas nucleares em uma região densamente povoada (ao contrário do Tratado da Antártica, de 1959, que cobre uma área desabitada). Analisando as estipulações do TNP, o Embaixador Celso Souza e Silva, representante do Brasil na Comissão de Desarmamento da ONU, em breve resumo histórico das discussões sobre a não-proliferação nuclear (XXX, 117-118, 1987), chamou a atenção para o Artigo VII, que assegura a qualquer grupo de Estados o direito de firmar tratados regionais, independentes do TNP, destinados a garantir a total ausência de armas nucleares nos respectivos territórios (caso do Tratado de Tlatelolco). Souza e Silva assinalou que a eficácia de qualquer zona livre de armas nucleares estaria "intimamente ligada ao respeito que as potências nucleares terão pela zona desnuclearizada”. De fato, o Protocolo Adicional II do Tratado de Tlatelolco obriga os cinco Estados nuclearmente armados a respeitarem o status desnuclearizado da zona e a não usarem armas nucleares contra os países da região ou ameaçá-los de uso (as chamadas "garantias negativas de segurança”). Deve-se registrar, porém, que, embora o Brasil se considerasse unilateralmente obrigado pelo Tratado de Tlatelolco, este só entrou de fato em vigor em 1994, depois de ter seu texto emendado e ratificado por todos os países latino-americanos, inclusive Cuba.

O choque do petróleo de 1973 teve um impacto brutal na economia brasileira e entre as polêmicas medidas tomadas pelo governo para contrarrestar seus efeitos sobressai o gigantesco programa nuclear. A construção de Angra I já havia sido acordada com os Estados Unidos, em 1972, mas o governo norteamericano se recusava a ampliar a cooperação por envolver o enriquecimento do urânio. Foi em 1975 que, dentro de uma estratégia de diversificação de parcerias, e com a finalidade de obter de terceiros o que os Estados Unidos se negavam a fornecer, assinou-se o Acordo Nuclear entre o Brasil e a República Federal da Alemanha, em Bonn, o qual causou sensação na época. A idéia era construir oito usinas nucleares com reatores de $1300 \mathrm{MW}$, do tipo PWR/Siemens, até 1990, e cerca de 50 outras usinas até o ano 2000 (!), incluindo enriquecimento do urânio para os reatores e o reprocessamento do combustível para obter urânio residual e plutônio. Daquele programa o que temos hoje é que a usina de Angra II só entrará em plena operação comercial em 1999 e ainda se discute se Angra III deve ser construída ou não.

No seio do estamento militar, havia ainda que veladamente a intenção de aproveitar a cooperação com a RFA para aumentar a capacidade tecnológica brasileira e obter os conhecimentos necessários para eventual fabricação da bomba atômica, objetivo não declarado que por muito tempo chegou a ser atribuído ao 
chamado "programa nuclear paralelo". Um dos argumentos dos militares para a obtenção do know-how para chegar a um artefato nuclear, além de conferir prestígio e de fortalecer o poder nacional, era o de que outros países já possuíam a bomba e, por isso, não poderia o Brasil voluntariosamente abdicar do domínio do conhecimento para construí-la se necessário fosse. Ao admitirem a possibilidade do "vir a ter", era muito difícil ao observador externo não desconfiar do "querer". A conhecida discussão sobre a autonomia excessiva dos militares no aparelho do Estado encontrava aí uma de suas realidades mais perversas.

Rex Nazareth Alves, ao escrever sobre o "O programa nuclear brasileiro" (XXX, 117-118, 1987), descrevia um quadro internacional repleto de dificuldades e restrições para a consecução das metas propostas: existência de cartel tecnológico restringindo o acesso à tecnologia e inviabilizando a compra de materiais e equipamentos; política e/ou legislação de países exportadores de tecnologia, equipamentos e materiais unificados, contrárias aos interesses nacionais; política de não-proliferação discriminatória e impeditiva de desenvolvimentos autônomos para fins eminentemente pacíficos; intenção declarada de não permitir o acesso de novos países ao mercado de tecnologias consideradas sensíveis; e interesse externo em manter o mercado brasileiro como importador de produtos com agregados tecnológicos e exportador de matérias-primas. Sob o pretexto de "garantir a paz mundial”, dizia-se, obstruía-se o “desenvolvimento independente e pacífico das nações emergentes”. Desse modo, a finalidade do "Programa Autônomo de Tecnologia Nuclear” seria a formação de uma competência nacional capaz de gerar as condições para a "independência indispensável ao atendimento pleno das necessidades brasileiras”, em um quadro de fortes pressões internacionais. No caso do Acordo Brasil-RFA, os Estados Unidos jamais cessaram de pressionar para que ele não prosperasse. Não obstante, no mesmo ano em que Rex Nazareth Alves escrevia (1987), o governo brasileiro anunciava que havia dominado por seus próprios meios o processo de ultra-centrifugação para o enriquecimento do urânio.

A política nuclear brasileira, no que se refere ao desarmamento e à nãoproliferação, começa a mudar com a redemocratização no Cone Sul, na década de 1980. Everton Vieira Vargas, diplomata de carreira, analisou em detalhe essa mudança no artigo "Átomos na integração: a aproximação Brasil-Argentina no campo nuclear e a construção do Mercosul”, já na Série Brasília da RBPI (Ano $\left.40, n^{\circ} 1,1997\right)$. A Declaração Conjunta sobre Energia Nuclear, assinada pelos Presidentes José Sarney e Raúl Alfonsín (Foz do Iguaçu, 1985), deu início à aproximação bilateral nessa área sensível, por meio de medidas de construção de confiança (como as inspeções mútuas em instalações militares), destinadas a garantir total transparência ao processo. Essa cooperação ganhou contornos mais amplos com o estabelecimento do Sistema Comum de Contabilidade e Controle (SCCC), em 1990, e o Acordo quadripartite para aplicação de salvaguardas entre 
o Brasil, a Argentina, a Agência Brasileiro-Argentina de Contabilidade e Controle de Materiais Nucleares (ABACC) e a Agência Internacional de Energia Atômica (AIEA), assinado em Viena, em 1991.

As suspeitas relacionadas com o "programa nuclear paralelo", levado a cabo sigilosa e autonomamente pelas Forças Armadas, foram finalmente sepultadas com o fechamento pelo Presidente Collor de Mello, em 1990, de um poço que presumivelmente serviria para testes nucleares na Serra do Cachimbo (uma área de treinamento militar no Estado do Pará). Sob o Governo Collor, assinala Everton Vargas, "a questão nuclear deixou de ser associada à busca da autonomia estratégica, como o fora durante o período militar e sob o Governo Sarney. A preocupação maior era com o acesso à tecnologia, e procurava-se um tratamento multilateral mais transparente que legitimasse essa opção". E continua: "Verificou-se uma revisão da estratégia de inserção internacional de cada um dos países [Brasil e Argentina], com uma disposição para se tornar parte do regime internacional de não-proliferação e seu conseqüente credenciamento como parceiros confiáveis, sobretudo no que se refere à utilização de tecnologias de duplo uso, isto é, aptas tanto para emprego civil quanto militar”. O fato é que, com essas medidas, o Brasil pretendia mostrar, de forma inequívoca e até mesmo inovadora, que estava dando passos concretos no campo da não-proliferação, mas fora do marco discriminatório do TNP. Ainda era aquela a marca do tempo.

Em 1995, o Presidente Fernando Henrique Cardoso anunciou que o Brasil não tencionava produzir, adquirir ou transferir mísseis militares de longo alcance (Declaração de São José dos Campos) e foi aprovada a Lei 9112, que dispõe sobre o controle de exportações nas áreas nuclear, química, biológica, missilística e convencional. Isso abriu caminho para que o Brasil aderisse, no mesmo ano, ao Regime de Controle de Tecnologias de Mísseis (MTCR), agrupamento informal de países para a coordenação de controles de exportação na área missilística. Entre os aspectos positivos do ingresso no MTCR, cumpre ressaltar os seguintes: coloca o Brasil ao lado dos países que detêm a tecnologia espacial e o poder de decisão na matéria; afasta o Brasil dos focos de fundada suspeita que atingem alguns países em desenvolvimento; consolida a imagem pacifista do país; e elimina a possibilidade de uso de legislações restritivas contra o Brasil, aplicáveis a países não-membros do regime.

Para um país que possui seu próprio programa espacial, integrar o MTCR pode não garantir per se cooperação espacial relevante com os países desenvolvidos, mas facilita o acesso a tecnologias que antes nos eram vetadas. A criação da Agência Espacial Brasileira, em 1994, subordinada diretamente à Presidência da República, reafirmou o controle civil sobre a Missão Espacial Completa Brasileira. Há grande interesse no desenvolvimento do Veículo Lançador de Satélites (VLS), pois o Brasil possui vantagem comparativa nesse campo: a base de Alcântara (MA), de localização geográfica privilegiada (a 2 graus da linha do Equador), 
reduz em até $25 \%$ os custos de lançamento. Como se sabe, o primeiro teste de lançamento do VLS, em novembro de 1997, não teve êxito, o que pode ser considerado normal. Mas o objetivo final permanece, ou seja, a entrada do Brasil no restrito e lucrativo mercado mundial de lançamentos de satélites.

Em 1996, a atividade diplomática do Brasil no campo do desarmamento foi ainda mais intensa: o Brasil aderiu ao Grupo de Supridores Nucleares (NSG), regime informal de países que visa à coordenação de controle de exportações de tecnologias e bens na área nuclear; ratificou a Convenção sobre a Proibição das Armas Químicas (que havia assinado em 1993), instrumento modelar na área do desarmamento, por se tratar de acordo efetivamente abrangente, não-discriminatório e verificável; assinou o Tratado para a Proibição Completa dos Testes Nucleares (CTBT), concluído naquele ano; e declarou uma moratória formal na exportação de minas terrestres antipessoal, por prazo de 4 anos, renovável por igual período (informalmente, a moratória já existia desde 1984).

O Brasil tomou ainda a iniciativa de propor Resolução à AssembléiaGeral da ONU, aprovada em 1996, sobre "O Hemisfério Sul e Áreas Adjacentes Livres de Armas Nucleares”, tendo em vista a existência de diversos instrumentos internacionais relativos a zonas livres de armas nucleares em regiões daquele Hemisfério: Tratados da Antártica (1959), Tlatelolco (América Latina e Caribe, 1967), Rarotonga (Pacífico Sul, 1985), Bangkok (Sudeste Asiático, 1995) e Pelindaba (África, 1996). Pela Resolução foi reconhecido o estatuto de desnuclearização para fins militares de quase todo o Hemisfério Sul, tendo sido feito apelo à conclusão de iniciativas análogas em outras áreas do globo.

Por fim, a iniciativa-síntese de tudo o que foi feito em termos de adesão a regimes de não-proliferação foi justamente a decisão do Presidente Fernando Henrique Cardoso de solicitar ao Congresso Nacional autorização para o ingresso do Brasil no TNP, em junho de 1997. Amadureceu a percepção de que, estando o TNP próximo a atingir a universalidade dos países, com 185 membros, já não fazia mais sentido para um país como o Brasil, que nada tem a esconder nessa matéria, seguir afastado das discussões sobre desarmamento, salvaguardas e outros temas, que ocorrem no âmbito do TNP e que são de interesse direto para o país. A adesão a esses regimes, em última análise, garantirá ao Brasil acesso facilitado a tecnologias sensíveis no campo nuclear para fins pacíficos, o que não era possível ou era muito dificultado pelos países desenvolvidos que tinham dúvidas sobre as reais intenções do país. Prevaleceu enfim, nesse campo, a força histórica da mudança.

\section{O poder militar no Brasil e o papel das Forças Armadas}

Parece haver, de forma inegável, uma co-responsabilidade civil-militar pelo escasso diálogo que por muito tempo foi a tônica nas relações entre as Forças 
Armadas e a sociedade civil no Brasil. A ausência de uma cultura estratégica consolidada no país explica apenas em parte esse fenômeno. Na RBPI, veículo natural para a divulgação da produção intelectual acadêmica, também foram publicados artigos representativos do pensamento dos militares, particularmente relevantes para a política externa se levarmos em consideração a natureza do regime de 1964-1985.

O General Carlos de Meira Mattos, um dos principais nomes da geopolítica que era largamente consumida nas casernas, abordou, em 1973, aspectos relativos ao poder militar e à política internacional, à guerra contemporânea (nuclear, limitada, convencional ou revolucionária), à estratégia (de ação direta ou indireta) e à diplomacia (XVI, 63-64, 1973). “Em síntese”, dizia Meira Mattos, “podemos dizer que o Poder Militar tem como principal instrumento as Forças Armadas e, como arte na aplicação desse instrumento, a Estratégia Militar”. A "Política Internacional", segundo ele, seria o "instrumento do Poder Político na busca de soluções pacíficas para os antagonismos entre as nações" e a diplomacia "a arte de negociar a serviço da Política Internacional”. Meira Mattos concluía afirmando:

"O Poder Militar vem sendo limitado na sua aplicação pelo perigo da hecatombe nuclear. A predominância, nos conflitos militares contemporâneos, é a das Guerras Limitadas ou Guerras Localizadas (combinando as formas convencional e revolucionária) e da estratégia de ação indireta. No âmbito da ação indireta salientamos a estratégia de dissuasão na qual se busca o efeito psicológico de paralização pela ameaça (ameaça nuclear no caso das superpotências). (...) Cabe à Política Internacional, por meio da diplomacia, a missão heróica de impedir que as desinteligências e antagonismos ultrapassem o campo das negociações, precipitando-se no campo da violência militar. Quando isto acontecer, mergulhada a nação na guerra, a missão do diplomata será a de reabrir o caminho das negociações, tendo sempre em vista a conquista ou manutenção dos objetivos nacionais. (...) A compreensão da Guerra Contemporânea, de suas implicações, é de importância capital na formulação de uma doutrina militar, na preparação e aplicação do Poder Militar. Dessa compreensão devem surgir medidas que possam contribuir para o fortalecimento do moral e do caráter nacional. A guerra, como fenômeno social, continuará existindo sob os diferentes tipos e formas, e devemos estar preparados para enfrentála como uma contingência da vida e da sociedade humana. Devemos compreender qual o gênero de guerra que nos ameaça, 'para que não incorramos no erro fatal de nos prepararmos para uma guerra errada, quase tão fatal como não nos prepararmos para nenhuma'."

Como a demonstrar o estímulo ao debate e a abertura da revista a todas as correntes de pensamento das Forças Armadas, a RBPI publicou, em 1984, artigo do Contra-Almirante Mucio Piragibe Ribeiro de Bakker, ex-Diretor da Escola de Guerra Naval, intitulado “O poder militar brasileiro: uma visão de suas 
particularidades” (XXVII, 105-108, 1984). Em abordagem distinta daquela de Meira Mattos, o autor discorreu sobre a presença militar na política nacional e as distorções e deficiências que tal fenômeno ocasionou historicamente ao poder militar brasileiro.

A partir de uma tendência que se iniciou após a Guerra do Paraguai, aumentou com a República a preocupação das Forças Armadas, especialmente do Exército, com a política interna do país, em detrimento de suas atribuições clássicas, cuja prioridade deveria ser, no caso, a defesa externa. Colaboraram para esse fenômeno os seguintes fatores: a participação dos militares na instauração e consolidação do regime republicano; a liquidação dos problemas fronteiriços no início do século XX , com a conseqüente redução das ameaças externas regionais, "únicas capazes de empolgar o Exército de um país sem responsabilidades extracontinentais"; e as preocupações crescentes do Exército com os problemas de segurança interna relacionados com "manifestações sócio-ideológicas" (Canudos, Contestado, etc.), que adquirem uma conotação anticomunista depois de 1917.

Mesmo após a Segunda Guerra Mundial, a tendência “doméstica” persistiu, uma vez que para os Estados Unidos, responsáveis pelo sistema de defesa hemisférica contra a União Soviética, não havia necessidade de que as Forças Armadas latino-americanas se preparassem para uma missão que cabia precipuamente à potência hegemônica realizar. Os militares brasileiros continuaram intervindo na política e, pela lógica da "guerra revolucionária", voltaram suas atenções para o "inimigo interno". Tal estado de coisas se agravou com o golpe de 1964, observa Mucio Bakker, devido ao "forte aumento da presença militar no governo, no sistema nacional de segurança interna e em instituições civis diversas, particularmente, mas não apenas, nos órgãos da administração direta e empresas estatais, tudo isso com respaldo doutrinário provido pela Escola Superior de Guerra”. A instrospecção estratégica daí decorrente só começou a ser reavaliada seriamente com a redução da intensidade da Guerra Fria, o contencioso de Itaipu com a Argentina e o conflito das Malvinas, eventos que puseram em evidência as distorções que haviam acometido o poder militar brasileiro.

Algumas dessas distorções foram bem apontadas por Mucio Bakker: tendência a promover ou contribuir para a formação de esquemas políticos propensos ao poder autoritário em detrimento de mecanismos de compromisso e acomodação, próprios do jogo democrático; propensão a privilegiar as práticas destinadas à segurança interna, relegando o preparo militar clássico ao segundo plano; tendência do poder militar a definir, ele próprio, o seu papel, com escassa interveniência da nação e de sua representação política; admissão de esquemas e mecanismos que respondem melhor às demandas de anseios pessoais (cargos, carreira, privilégios, projeção, conforto e outros) do que à objetividade militar profissional; e ausência de orientação para que as três forças singulares tenham 
seus preparos comandados por diretrizes coerentes entre si e fundamentadas em percepções e avaliações comuns a respeito das hipóteses de ameaça. $\mathrm{O}$ autor conclui propondo um esforço do governo para a reformulação conceitual do preparo militar (naval, terrestre, aéreo e integrado), o qual deveria enfatizar a defesa externa e o profissionalismo clássico, em consonância com a missão constitucional das Forças Armadas. A título de ilustração, é sempre bom reter que, de acordo com o Artigo 142 da Constituição de 1988, as Forças Armadas se destinam "à defesa da Pátria, à garantia dos poderes constitucionais e, por iniciativa de qualquer destes, da lei e da ordem”.

O Coronel Geraldo Lesbat Cavagnari Filho, atual Coordenador do Núcleo de Estudos Estratégicos da Unicamp, contribuiu na RBPI com algumas de suas reflexões sobre a estratégia aplicada ao caso brasileiro no artigo "Brasil: introdução ao estudo de uma potência média” (XXVII, 105-108, 1984). Cavagnari observa que o discurso diplomático é explícito quanto às intenções da política externa brasileira, quando "rejeita o status de potência hegemônica como condição para fortalecer a presença internacional do Brasil, a fim de não reproduzir em outro nível as relações que hoje estão sendo condenadas pelos países subdesenvolvidos”. E continua:

"Por enquanto, a diplomacia brasileira está convencida de que os interesses estratégicos brasileiros limitam-se à América do Sul, onde a presença diplomática se completa como presença estratégica. Reconhecendo que o País tem reduzida capacidade militar em relação à amplitude de seus interesses internacionais, com escassas possibilidades de influir no cenário mundial pela força, a diplomacia brasileira é sensível, em termos de segurança, apenas àqueles acontecimentos políticos que possam afetar o equilíbrio sul-americano de poder”.

Opõe-se a essa visão, segundo Cavagnari, o triunfalismo do discurso geopolítico, preocupado em demonstrar que o Brasil até o final do século será uma grande potência. Em tese, a maioria dos esquemas geopolíticos projeta uma pretensa hegemonia brasileira na América do Sul e superestima a participação atual do Brasil no processo decisório mundial. "Essa avaliação”, critica o autor, "decorre da metodologia utilizada pela geopolítica, que consiste na abordagem dos fatores geográficos (em resumo, o espaço e a posição) organizados em torno de determinados indicadores absolutos (isto é, o tamanho do PNB, a extensão territorial, os recursos naturais e a população), não levando em consideração o aspecto qualitativo desses indicadores, o grau de segurança desejável para a sociedade civil e a capacidade real do País na organização das relações de poder mundiais”. Isso o leva a considerar a visão diplomática sobre a realidade brasileira mais sensata do que o discurso geopolítico, por reconhecer "a existência de problemas internos típicos do subdesenvolvimento (concentração de renda e grandes deficiências em saúde, alimentação, habitação e educação) e de uma situação de dependência no sistema econômico internacional (importador de capital e tecnologia)". 
Cavagnari conclui que o cenário estratégico para o Brasil, como potência média, está contido nos limites da América do Sul. A posição que o Brasil ocupa na hierarquia de poder mundial, no entanto, como primeiro país sul-americano, concede-lhe, por extensão, o status de maior potência regional. A partir disso, pode-se dizer que, como queria a geopolítica, o Brasil estaria fadado à hegemonia no continente? A resposta é não:

“A limitação à autonomia estratégica do Brasil é conseqüência da hegemonia exercida pelos EUA, na América Latina, que praticamente lhe subtrai a vantagem de poder em relação aos países sul-americanos e lhe restringe o uso da força à defesa da integridade territorial e da soberania nacional, quando ameaçados. É uma imposição que resulta da integração de todo o espaço mundial nos esquemas de poder administrados pelas superpotências. (...) Assim, o uso autônomo da força por uma potência regional se anula devido à sua incapacidade para subverter com êxito a relação de hegemonia imposta”.

Artigo mais recente sobre "O pensamento dos militares em política internacional (1961-1989)”, escrito pelo autor desta resenha, publicado já na série Brasília da RBPI (Ano 40, n 1, 1997), tratou de questões relacionadas à evolução do pensamento dos militares brasileiros em matéria de relações internacionais e política externa. A partir de conclusões de diversos especialistas na área, entre eles Shiguenoli Miyamoto, Eliézer Rizzo de Oliveira e Antonio Carlos Pereira, o texto expôs algumas das limitações da "interpretação crítica tradicional”, que pretendia explicar a condução da política exterior do Brasil, no período do regime militar, exclusivamente à luz da Doutrina de Segurança Nacional e da geopolítica. Ao se analisar a concepção de política internacional prevalecente nos ensinamentos doutrinários das Forças Armadas, ficou claro o peso do realismo político clássico, cuja influência perdura ainda hoje. Por mais que tenha evoluído o pensamento dos militares no pós-Guerra Fria, há resistências à mudança que se originam da própria natureza do ofício e da missão a eles destinada.

Entre os traços distintivos que marcaram o pensamento dos militares, não parece haver dúvida que o nacionalismo que lhes é característico encontrou sua melhor tradução na busca sistemática e consciente de uma posição mais elevada para o Brasil no quadro mundial, que se pensava compatível com o potencial de um país de dimensões continentais: "O robustecimento do poder nacional permitiria ao Estado brasileiro fazer-se forte o bastante para, em um mundo dominado pela lógica fria dos interesses, abrir seu próprio caminho visando à criação de um novo centro de poder independente na América do Sul”. Os militares entendiam que a emergência de novo centro de poder político não poderia admitir a subordinação estratégica ad infinitum ao poder hegemônico.

O caminho seguido, portanto, foi o da autonomia estratégica, a ser alcançada através da nacionalização dos meios, da redução da dependência e das vulnerabilidades nacionais, e de maior liberdade de manobra logística e operacional, 
com vistas a impedir a transferência dos centros de decisão para o estrangeiro e a garantir a soberania plena do país em todos os campos do desenvolvimento. $\mathrm{O}$ caminho autonomista acabou por gerar uma mística associada à capacidade das Forças Armadas de serem indutoras em última instância do desenvolvimento científico e tecnológico, mística esta que os projetos especiais dos militares só faziam reforçar.

Qual o papel que cabe ao poder militar brasileiro? Não há respostas simples. Antes de entrar no próximo item, que continuará a abordar esse tema, haveria que lembrar, finalmente, o crescente engajamento das Forças Armadas nas operações de paz das Nações Unidas, vertente que tem ganho impulso na política externa brasileira. O Brasil tem participado de operações de manutenção da paz com mais intensidade nesta década, o que tem-se revelado boa oportunidade para o exercício de atividades específicas pelas Forças Armadas (cessões de tropas, observadores, policiais, equipes médicas, etc.), em situações que dificilmente teriam lugar em um conflito no qual o Brasil estivesse diretamente envolvido. Em Angola, por exemplo, o Brasil é o maior contribuinte com tropas na UNAVEM-III (cerca de 1500 voluntários). Essa participação, além de colaborar para a solução negociada de conflitos (respeitados os princípios do consentimento prévio das partes, da imparcialidade e da não-violência) contribui não só para a projeção internacional do país como também é útil para o aprimoramento do preparo militar e para a atualização de conhecimentos, pelo contato com Forças Armadas de outros países.

\section{Segurança e política de defesa do Brasil}

A segurança está em uma escala baixa nas prioridades nacionais, fato compreensível para um país pacífico que não alimenta pretensões hegemônicas no continente nem se sente ameaçado pelos seus vizinhos. Com a perda de substância das três hipóteses de guerra que haviam dominado o pensamento militar brasileiro desde os anos 60 (envolvimento ao lado do bloco ocidental em um confronto Leste-Oeste, conflito com a Argentina e guerra revolucionária interna), mudou a percepção da ameaça e novas prioridades foram surgindo.

A aproximação Brasil-Argentina e o estabelecimento do Mercosul fizeram a hipótese de conflito na fronteira Sul cair a zero. Em contrapartida, a problemática fronteira Norte exige crescente atenção, pois nela o tema tradicional da vigilância das fronteiras convive agora com a necessidade de preservação do meio ambiente, de combate ao crime organizado, ao contrabando e ao narcotráfico, embora não se espere que as Forças Armadas façam o trabalho que compete à esfera policial. Os gastos militares per capita do Brasil, são pequenos, compatíveis com os atuais cenários regional e internacional. Entretanto, o aparelhamento das Forças Armadas, do ponto de vista estritamente defensivo, envolve uma força mínima de dissuasão, à qual poderia ser somada, no cálculo estratégico, uma capacidade 
potencial de mobilização militar como resposta a ameaças. Como poderia ser, então, planejada e pensada uma política de defesa nacional? A experiência histórica recente do Brasil talvez comporte alguns ensinamentos.

Em 1978, na RBPI, Clóvis Brigagão, acadêmico ligado à área de segurança e estratégia, publicava análise sobre o cancelamento do Acordo Militar BrasilEstados Unidos, ocorrido no ano anterior (XXI, 81-84, 1978). O Governo Geisel denunciou o Acordo como reação imediata às condições impostas pelo Congresso norte-americano à abertura de uma linha de crédito da ordem de US\$ 50 milhões (referente a assistência militar para equipamentos), condicionando-a a um relatório sobre violação dos direitos humanos no Brasil. Brigagão tratou dos antecedentes da questão e do contexto histórico que levou à assinatura do Acordo durante o segundo Governo Vargas, em 15 de março de 1952, contribuindo assim para que o público leitor da Revista pudesse ter elementos de informação para formar sua própria opinião a respeito daquele significativo acontecimento. O Acordo nunca estabeleceu uma política consistente de transferência de tecnologia dos EUA para o Brasil, consistindo basicamente de fornecimento de equipamentos e materiais usados (quando não obsoletos). Em 1977, o Acordo já se encontrava na prática inoperante, e seu rompimento representou, acima de tudo, gesto político de marcante significado para os militares na busca da autonomia estratégica do país. Como assinalado por Brigagão:

"O crescimento da indústria manufatureira, particularmente de veículos motorizados e setores da mecânica, metalurgia, eletrônica, etc., foram incrementados para abastecer uma ampla gama de equipamentos terrestres, incluindo caminhões militares, tanques e veículos blindados. Ao mesmo tempo, essa estrutura bélica vinculada a centros e institutos de pesquisa e desenvolvimento no campo militar, inclusive Universidade, de modo a assegurar continuidade e atingir novos níveis de sofisticação, tanto nas áreas do Exército, Aeronáutica e Marinha. Toda essa política de modernização, iniciada em 1967, desdobra-se com maior vigor a partir de 1975 com a criação da IMBEL (Indústria de Material Bélico do Brasil). A IMBEL foi concebida como uma holding vinculada a centenas de indústrias privadas que operam hoje na produção de armamentos. Um de seus objetivos é tornar o Brasil auto-suficiente em armamentos e com capacidade para exportar. Sua política foi traçada no sentido de incentivar a competição do mercado nacional de armas e, mais tarde, lançar-se na competição do mercado internacional, o que vai ocorrer principalmente a partir de 1978”.

Como as Forças Armadas não poderiam sozinhas garantir a compra de tudo quanto fosse produzido internamente, o modelo para o desenvolvimento da indústria bélica brasileira foi calcado na produção para a exportação de material de tecnologia intermediária, em especial para mercados em países em desenvolvimento (África, Oriente Médio, etc.). As exportações seriam formalmente controladas pelo Programa Nacional de Exportação de Materiais e Equipamentos 
Militares (PNEMEM), concebido pelo Conselho de Segurança Nacional. A busca desses mercados coincidiu com o "pragmatismo responsável” da política externa brasileira, de ímpeto mais comercial e menos ideológico do que opções diplomáticas anteriores, e deu origem a parcerias com países que depois se revelaram um problema a resolver, como Líbia, Irã e Iraque.

O Brasil se tornou em dado momento o maior produtor de armas do Terceiro Mundo, estando a maior parte da produção concentrada no complexo militar-industrial de São José dos Campos (SP). Além da IMBEL, já mencionada, três grandes empresas estiveram à frente desse processo: a Engesa (Engenheiros Especializados S/A), empresa privada fabricante dos carros de combate Urutu e Cascavel; a Embraer (Empresa Brasileira de Aeronáutica), empresa mista controlada pelo Estado (que detinha 51\% das ações), construtora do avião de treinamento Tucano e integrante da joint-venture Brasil-Itália para o desenvolvimento do caça a jato subsônico AMX; e a Avibrás, empresa privada colaborando em estreita associação com o Centro Tecnológico da Aeronáutica (CTA), fabricante do lançador múltiplo de foquetes de saturação Astros 2.

Fatores internos (falta de condições do setor público para injetar novos recursos) e externos (retração do mercado externo, em especial no Oriente Médio) decretaram a falência do modelo na virada da década de 1990. Com a crise profunda da indústria bélica brasileira, as três empresas, que chegaram a responder por 95\% das exportações de armas do Brasil, sofreram duro golpe: a Engesa entrou em concordata, em 1990, e teve sua produção desativada; a Avibrás foi obrigada a diversificar sua produção para não fechar, fabricando desde então tubos sem costura, antenas parabólicas e outros equipamentos de telecomunicações; e a Embraer, endividada, foi enfim privatizada em 1994, tendo conseguido se soerguer graças à boa aceitação no mercado internacional de suas aeronaves comerciais, como o EMB-145 (a Embraer foi a única das "três grandes” a alcançar nessa transição relativo sucesso).

Além da indústria de armamentos e da política nuclear (já abordada nesta resenha), o outro componente da "modernização autoritária" (ou da política de defesa?) pretendida pelos governos militares, ao qual convém pelo menos fazer menção, era a indústria da informática. As discussões sobre o desenvolvimento autóctone desse setor no Brasil ganharam corpo nos anos 70, posteriormente consubstanciadas na reserva de mercado e nas políticas de "capacitação nacional" implementadas pela Secretaria Especial de Informática (SEI) de 1978 a 1984 . O contencioso Brasil-Estados Unidos daí originado só veio a ser contornado com a abertura da economia brasileira no início dos anos 90, mas uma análise sobre o assunto fugiria dos objetivos desta resenha.

Outra área tradicional de preocupação para a defesa nacional, já mencionada, é a fronteira Norte e seus grandes espaços amazônicos, onde a dificuldade de acesso e a baixa densidade demográfica colocam problemas de 
ordem logística para sua adequada cobertura estratégica. Em 1968, a RBPI publicou número especial sobre a Amazônia (XI, 41-42, 1968), com artigos tais como: "Por que a Amazônia deve ser brasileira” (Arthur Cezar Ferreira Reis), “Amazônia: desafio e contribuição” (Armando Dias Mendes), "Um sistema sul-americano de grandes lagos” (Robert Panero), “Novo enfoque sobre a Amazônia” (Herman Kahn \& Robert Panero), "Diretrizes de uma planificação para o desenvolvimento regional da Amazônia" (Frederico Rondon), "Uma solução global para o problema do Amazonas" (Eudes Prado Lopes), e "Recursos naturais e humanos da Amazônia" (Felisberto Camargo). O mote das discussões era então a proposta do Instituto Hudson de construir barragens para criar cinco grandes lagos na Bacia Amazônica, pretendendo com isso estimular o intercâmbio econômico entre os países da América do Sul e o investimento estrangeiro na região (pesca, mineração, etc.), proposta esta que enfrentou fortes reações contrárias no Brasil e que, por isso mesmo, nunca avançou.

O artigo do General Rodrigo Otávio Jordão Ramos, “As Forças Armadas e a integração da Amazônia”, no já citado número especial da RBPI sobre "Temas Militares” (XIV, 53-54, 1971), reflete bem a visão militar sobre a Amazônia, que tomou corpo à época do "milagre” brasileiro, ou seja, de integrar a região ao resto do país pela ocupação humana dirigida e estimulada pelo Estado, via migrações internas e assentamentos de colonos (os “excedentes demográficos nordestinos”) às margens das rodovias que deveriam desbravar e ajudar a desenvolver a floresta, como a Transamazônica e, do ponto de vista da segurança ao longo da fronteira, a Perimetral Norte. "Integrar para não entregar” era o lema que animava a "verdadeira bandeira nacionalista” contra a "cobiça” estrangeira:

"Afanosamente luta-se hoje para que o terceiro Brasil (o Brasil infradesenvolvido) não mais se detenha em sua arrancada definitiva (ainda que cautelosa e limitada pelos meios e instrumentos proporcionados) revigorando-se como medida preliminar e básica o enquadramento de segurança existente de forma a permitir, não só enfrentar as pressões exógenas, cada vez mais intensas, pela vitalização dos núcleos fronteiriços alienígenas já ligados ou em vias de conexão nos seus Centros de poder secundário e principais, como sobretudo pelos antagonismos eventualmente surgidos na zona interiorana, derivados de pressões endógenas de núcleos autóctones imigrados de cultura mais avançada, com valor cada vez mais ponderável, ou ainda de capitais ou de técnicas estrangeiras que busquem aplicação mais rendosa às suas atividades, os quais, todos, deverão ser contidos intransigentemente dentro dos limites fixados pelo interesse nacional".

Nessa mesma linha, o projeto Calha Norte, que permaneceu sigiloso até 1986, pretendia estabelecer focos de presença efetiva em áreas remotas de fronteira na Amazônia, a partir de núcleos urbanos ("pólos de irradiação de desenvolvimento”) como as cidades de Tabatinga e São Gabriel da Cachoeira, 
ambas no Estado do Amazonas. A maior parte da execução do projeto ficou a cargo do Exército, que, por falta de recursos, continuou a tocá-lo em marcha lenta. Houve, é certo, uma mudança de concepção com o projeto Sivam (Sistema de Vigilância da Amazônia), destinado a criar uma rede integrada de telecomunicações, sistemas de sensores e radares conectados por satélite, aparelhos para interceptação e localização de sinais magnéticos, aviões e equipamentos de comunicação, tudo voltado para o monitoramento estratégico da região amazônica, coleta de dados, controle do tráfego aéreo e produção de informações para o planejamento governamental da ocupação e do desenvolvimento sustentável da região. O Sivam substituiu a idéia de presença física para a de controle à distância, com base na inteligência e na informação.

Por trás da concepção do Calha Norte estavam os mesmos antigos temores dos militares pela "internacionalização da Amazônia", que de tempos em tempos assume diversas feições "concretas", como a hipotética criação de um Estado yanomami. Essas visões conspiratórias, próprias do soberanismo, encontram-se tão arraigadas que produzem situações inusitadas, como a que se verificou por ocasião do recente incêndio que devastou Roraima, quando a ajuda estrangeira foi inicialmente rejeitada por oficiais do Exército. Aquele foi um claro indicativo de que, para os militares, a defesa da soberania (em termos territoriais ou abstratos) poderia implicar algum sacrifício do patrimônio ecológico do país. Somente estruturas mentais e percepções construídas em toda uma formação, das escolas militares aos cursos de alto comando, podem explicar a persistência de tal viés soberanista. A marca do tempo, neste caso, ainda não foi superada pela força histórica da mudança.

Com relação ao Atlântico Sul, outra área de interesse estratégico para o Brasil, em especial para a atuação da Marinha, cumpre recordar a Resolução 41/ 11 da ONU, de 1986, que, por iniciativa brasileira, aprovou a declaração da Zona de Paz e Cooperação do Atlântico Sul. Em 1981, o Brasil havia chegado à Antártica e, no ano seguinte, a Guerra das Malvinas mostrou de maneira dramática que uma área vital para a defesa nacional (a fronteira Leste) estava desguarnecida e vulnerável sob todos os aspectos, inclusive no plano da articulação jurídicodiplomática entre os países dos dois lados do oceano. Do ponto de vista da diplomacia brasileira, a Resolução de 1986, malgrado seu caráter eminentemente declaratório, serviria como uma espécie de "escudo conceitual” para dissuadir eventuais ações militares de potências extra-regionais, bem como para implementar, no longo prazo, um sistema de cooperação horizontal que salvaguardasse o uso pacífico do mar entre os Estados ribeirinhos, segundo a comunidade de interesses e a responsabilidade primordial de todos para com o hidroespaço atlântico.

O Capitão de Mar-e-Guerra Acânio José Leão, no artigo "Interesses regionais e extra-regionais no Atlântico Sul” (XXXII, 127-128, 1989), assinalava que os direitos do Brasil aos recursos marinhos disponíveis em seu mar territorial, 
plataforma continental e, sob certas condições, fundos marinhos do alto-mar, seriam assegurados pelo estabelecimento de uma política externa "competente", que desenvolvesse esforços no sentido de evitar que as justas aspirações do Brasil fossem preteridas, por ocasião de negociações, e que criasse condições para a paz e a estabilidade econômica e social na região banhada pelo Atlântico Sul. “Ao Poder Naval”, dizia ele, caberia "respaldar a Política Externa, através de ações de presença e de participação em estratégias de dissuasão”. Para tanto, sugeria:

"De fato, embora o Brasil não considere o Atlântico Sul como sendo o seu 'quintal', a magnitude de seus interesses, nele concentrados, implicam pesadas tarefas de segurança, que somente serão executadas com eficiência se, através de uma Marinha dotada de meios adequados, mantivermos constante presença em todos os pontos de sua área. (...) Mesmo considerando que o Brasil não possui aspirações expansionistas, que não deseja projetar o seu poder sobre o território de outras nações, mas, tão somente, ver respeitados os seus direitos, seria desejável contar com um Poder Naval capaz de executar as seguintes tarefas: controlar áreas marítimas, negar o uso do mar ao inimigo, projetar poder sobre terra e promover a dissuasão naval clássica. (...) Julgamos ser imprescindível que esse planejamento [do Poder Naval Brasileiro] inclua, obrigatoriamente, a nacionalização, não somente das plataformas, mas, também, dos sistemas, equipamentos e componentes. Aproveitando a capacidade de nosso parque industrial, a tecnologia transferida para os nossos técnicos, a partir do momento em que foi intensificado o programa de construção naval no país e os resultados das pesquisas realizadas no âmbito da Marinha e das demais Forças Singulares, poderemos reduzir, de uma forma gradual e persistente, a nossa dependência tecnológica”.

O projeto-símbolo da Marinha para a redução da dependência tecnológica do estrangeiro foi o do submarino de propulsão nuclear. A argumentação estratégica para que o Brasil tivesse esse tipo de submarino incorporado à sua esquadra baseava-se na ampliação do perímetro de defesa da fronteira marítima, já que o submarino nuclear, por sua discrição e grande autonomia de operação (ao contrário do submarino convencional, que precisa se reabastecer de combustível), poderia cobrir áreas mais distantes por mais tempo, tornando mais difícil o exercício de ameaça ao Brasil pelo mar. A argumentação técnica, por sua vez, tinha como fundamento a idéia de que, para países do nível tecnológico do Brasil, uma meta tão complexa só poderia vir a ser atingida com esforço próprio, pois nenhuma grande potência cooperaria em um projeto militar com potencial para contrarrestar sua própria superioridade naval. Teria de ser desenvolvido no próprio país o domínio do combustível (tratamento do minério ao urânio enriquecido), da tecnologia do reator e das tecnologias associadas aos equipamentos de máquinas (gerador de vapor, trocadores de calor, turbinas, bombas, motores elétricos e outros), objetivo das pesquisas realizadas no Centro Experimental de Aramar, em Iperó (SP). O projeto, iniciado em 1978, era conhecido como "Programa Chalana”. O submarino 
nuclear seria, assim, como meta de longo prazo da Marinha, mais um passo a ser dado rumo à autonomia estratégica.

A visão autonomista não era exclusiva do estamento militar e encontrava eco em outros segmentos da sociedade brasileira. O Embaixador Celso de Souza e Silva, apenas para dar um exemplo representativo de parcela do pensamento diplomático, em seu artigo "A posição relativa do Brasil no quadro estratégico mundial” (XXXIV, 133-134, 1991), postulava enfaticamente que o Brasil deveria "contar com seus próprios esforços e recursos, como quase sempre fez, sem confiar na panacéia eventual e aleatória da colaboração externa como fator preponderante para o seu desenvolvimento".

A série Brasília da RBPI, inaugurada em 1993, reflete um debate posterior ao reconhecimento de que o modelo nacional-desenvolvimentista se tinha exaurido historicamente e que era mister repensar a inserção do Brasil em um mundo de globalização econômica. Na esfera da segurança, Thomaz Guedes da Costa, pesquisador do Centro de Estudos Estratégicos (SAE/PR), da Universidade de Brasília e do $\mathrm{CNPq}$, tratou em dois artigos de questões afetas à nova maneira de pensar que as transformações no cenário internacional impunham ao pensamento estratégico: "Política de defesa: uma discussão conceitual e o caso do Brasil" (Ano 37, $n^{\circ}$ 1, 1994) e "Conjecturas sobre Grande Estratégia e os países do Cone Sul” (Ano 39, n 1, 1996). Enquanto neste último foram discutidas as grandes estratégias da Argentina, do Chile, do Paraguai e do Uruguai na nova configuração da ordem internacional, tendo em vista a importância desses países para o Brasil, no primeiro Thomaz Guedes enfocou aspectos operacionais do conceito de política de defesa nacional, entendida como "o conjunto formado por princípios gerais, por processos de tomada de decisão e de alocação de recursos e pela implantação de medidas para o preparo e o emprego das Forças Armadas como instrumento de ação do país na preservação ou consecução de interesses na cena internacional”. A política de defesa possuiria quatro componentes básicos: os segmentos do discurso, do emprego, do preparo e da aquisição de armamentos. Depois de analisar esses quatro segmentos no caso brasileiro, o autor conclui:

"A análise sugere que se faz necessário estabelecer abordagens novas, tanto para a gestão eficaz da defesa nacional, quanto para o estabelecimento de diretrizes estratégicas para a orientação das unidades governamentais brasileiras. O Brasil só poderá assegurar seus interesses, capacitar suas Forças Armadas, garantir acesso às tecnologias modernas e usos dessas tecnologias e integrar o emprego das forças armadas de forma viável e eficaz, como instrumento da estratégia nacional, se estabelecer uma unidade de pensamento, pelo menos em nível de Executivo”.

A adoção do documento de Política de Defesa Nacional, anunciado pelo Presidente Fernando Henrique Cardoso, em 1996, ao enumerar princípios, definir objetivos e traçar diretrizes para a atuação do Estado brasileiro na área de defesa, 
significou um avanço na linha sugerida por Thomaz Guedes da Costa. No entanto, essa certamente é uma tarefa em contínua evolução e a Revista Brasileira de Política Internacional, como o fez nos últimos 40 anos, estará aberta para acolher contribuições de toda a sociedade e continuar a promover o debate sobre as grandes questões estratégicas do Brasil e do mundo contemporâneo.

Março 1998 